\title{
Identifying Digital Transformation Paths in the Business Model of SMEs during the COVID-19 Pandemic
}

\author{
Anjar Priyono *(D), Abdul Moin $(\mathbb{D}$ and Vera Nur Aini Oktaviani Putri $\mathbb{D}$ \\ Department of Management, Universitas Islam Indonesia, Yogyakarta 55283, Indonesia; \\ abdul.moin@uii.ac.id (A.M.); veranuraini80@gmail.com (V.N.A.O.P.) \\ * Correspondence: anjar.priyono@uii.ac.id
}

Received: 10 September 2020; Accepted: 30 September 2020; Published: 3 October 2020

\begin{abstract}
The objective of this study was to analyze how small and medium enterprises (SMEs) cope with environmental changes due to the COVID-19 pandemic by pursuing the business model transformation with the support of digital technologies. To achieve the objective, this study used a multiple case study design with qualitative analysis to examine the data obtained from interviews, observation, and field visits. Seven manufacturing SMEs from Indonesia were selected using a theoretical sampling technique, with the purpose of achieving some degree of variation to allow us to undertake replication logic. Our analysis demonstrates that SMEs adopt a different degree of digital transformations, which can be summarized into three paths, depending on the firms' contextual factors. First, SMEs with a high level of digital maturity who respond to the challenges by accelerating the transition toward digitalized firms; second, SMEs experiencing liquidity issues but a low level of digital maturity who decide to digitalize the sales function only; and, third, the SMEs that have very limited digital literacy but are supported by a high level of social capital. This last group of firms solves the challenges by finding partners who possess excellent digital capabilities. The qualitative case study method allows us to conduct in-depth and detailed analysis, but has thin generalizability. To address this limitation, future research can use a survey covering various industries to test the proposed theory that has resulted from this study, so that the generalizability can be assured.
\end{abstract}

Keywords: digital technology; business model innovation; digital transformation; dynamic capability; organizational agility; learning organization; open innovation

\section{Introduction}

The COVID-19 pandemic has caused dramatic environmental changes that encourage firms to adopt digital technology on a wider scale and under time pressure. The firms have attempted to adopt it in a matter of days, because the slower it is adopted, the bigger the gap will be regarding the changes needed in the business environment [1]. In addition, employees who work remotely have increased the need for firms to urgently undertake digital transformations; otherwise, the firms cannot operate properly [2,3].

In times of disruptive changes, such as now, many firms still assume normal conditions in their planning process and thus implement annual or multi-year planning. The plan that results from this approach can still be used but has much less relevance [4], while an emergent approach with a flexible strategy is viewed as more relevant [5]. The traditional linear approach, which refers to long-term strategic planning, is replaced by an iterative approach which requires a calibration between execution and planning [6].

It is believed that digital technology enables firms to transform business models quickly, and not in traditional or linear ways [6]. Digital transformation is defined as the initiative of firms to use 
new capabilities by leveraging digital technologies in order to transform organizational strategies and operations [4]. Digital technology has capabilities that we could never even imagine just a few years ago. Some examples include 5G, artificial intelligence, or 3D printing [7]. The shortening time gap between the emergence and utilization of digital technology, the journey path, and the final destination of digital transformation are difficult to define precisely in advance [4]. On the other hand, organizations must be able to identify external stimuli [8], and digital technologies are viewed as being alternatives that firms can use to respond to these stimuli.

The transformation of the business model, supported by digital technology, has been documented in the literature as one of the strategies used to respond to disruptive environmental changes; in particular, technologies that support firms in the identification of new business practices [9]. For this reason, digital technologies are viewed as a suitable response to the disruptive changes caused by the COVID-19 pandemic. The impact of the pandemic is different and more dramatic than the traditional one, in which changes are driven by human innovation [8,9]. In such conditions, managers focus more on how to rescue firms from bankruptcy rather than on creating a sustainable competitive advantage [10]. The adjustment to this external stimulus should be undertaken continuously, and not just be one action [3].

Scholars have documented that established firms experience higher failure rates when they transform their business models [11]. Meanwhile, in a disruptive environment, managers can no longer see digital technologies as a supporting function; but should instead be part of a company's business innovations. In order to shift this paradigm, managers need to reconstruct their existing mindsets [12].

Although several types of companies have been able to adapt creatively with the support of digital technologies, the journey to becoming digital is challenging for small and medium enterprises (SMEs) operating in creative industries that manufacture physical products, which are not categorized as essential during the pandemic [13]. We acknowledge the previous literature on business model transformation $[3,13]$, and even though it is not supported by granulated empirical data, it provides a theoretical foundation for our empirical research. We have also benefited from previous research that used empirical data even though the subject was start-ups attempting to adjust their business models as a result of the COVID-19 pandemic, rather than SMEs [10]. However, the question of how the process of conducting the business model transformation and what elements become the focus of transformations remain unanswered and this leaves a knowledge gap. Thus, conducting research addressing this issue with SMEs as subjects would offer significant contribution to knowledge in the area business model, information technology, and innovation. The need to conduct digital transformation quickly, in a matter of weeks or even days, becomes paramount during a pandemic due to the disruptive changes it causes. The failure to pursue this transformation could widen the technology gaps with competitors [1]. Thus, two relevant research questions are:

(1) What are the challenges experienced by SMEs during the crisis caused by the COVID-19 pandemic?

(2) How does the SMEs' digital transformation process cope with these challenges?

\section{Literature Review}

\subsection{Business Model in Established SMEs}

In normal conditions, established SMEs develop a new business model. The aim is either diversification or to make this new model a substitute for existing business models that are starting to fade [14]. No firms can achieve success by permanently relying on an existing business model because they are under pressure from external forces to continuously reinvent it with the use of digital technologies [3]. Meanwhile, many traditional organizations pursue the digitalization journey toward more digitalized business models, and look forward to implementing digital technologies in every function to support their operations [15].

Although large firms are supported by more established infrastructures and lower fixed costs of production, SMEs are able to operate in a local business environment and can explore alternative 
strategic options more quickly [15]. In addition, SMEs have demonstrated elasticity and flexibility to carry out strategic maneuvers so they can make adjustments quickly in uncertain conditions [16]. Meanwhile, large sized firms can achieve organizational flexibility when their digital technology adoption has reached a maturity phase. Organizations with a low level of organizational digital maturity cannot accelerate the maturity process by using a shortcut of simply recruiting vendors who offer "outside the box" solutions [15].

The creation of new business models in an established company can increase the organizational complexity [14] and, therefore, the organizational design must be adjusted to accommodate this complexity [17,18]. Core rigidities [19] and resource stickiness [20] are possible issues that may arise when firms are about to pursue a radical business model transformation. Unlike start-ups that can move flexibly, it is most likely that traditional firms will experience conflict between the newly developed business model and the existing one [21]. Apart from these potential problems, the benefits of a new business model for the firms' performance remain inconsistent [22].

Established firms that cannot seize opportunities from environmental changes will be replaced by those who take advantage of the digital technology that has resulted from them pursuing transformation in creative ways [23]. Managing retail store outlets is burdensome due to the fixed cost involved but if these distribution channels could be synergized with the digital business model in a creative way, firms could capitalize on their existence [15]. Digital technology has changed the position of established firms in various industries and led to the emergence of new players from different industries that had never been imagined previously [24]. In addition, many new, flexible competitors have emerged because they are supported by asset light business models, such as Uber, Grab, Airbnb, and digitally-based companies with similar business models.

\subsection{Digital Technology-Based Business Model Transformation}

Business model transformation with the support of digital technologies can be carried out by using two methods: recombination and invention. Recombination is undertaken by combining new business models with the existing one in one or more business model dimensions. Meanwhile, invention is carried out by developing a completely new business model. This is done by first defining the value proposition and then followed by designing other value dimensions [12]. Traditional methods of strategic planning cannot catch up with the disruptive changes that result from digital technologies. This is because traditional planning does not include the disruption caused by the non-linear nature of technological development [6].

The dynamism, uncertainty, and complexity of the business environment, including the disruptive change caused by the COVID-19 pandemic, can all be major triggers that spark the transformation toward digital business models. Digital technologies can transform the core value that is offered to customers that make new business models more relevant to the emerging business environment [8]. The characteristics of the digital business models differ from the characteristics of the traditional model in that many of the activities can be replicated at almost negligible costs [25]. Another fundamental difference is that the digital business model is customer-centric, as the target market and the dimensions of value offered by the business models must be defined from the customers' perspective [12]. Transforming a business model into digital can be categorized as successful if the newly-formed business model changes fundamentally [12], particularly in the following three dimensions: value creation, value delivery, and value capture [26].

Digital technologies, combined with organizational capabilities and resources, can produce fundamental changes, particularly in how firms create and capture value [27]; and these kinds of changes to business models make future competition difficult to foresee [28]. It is easier for firms to execute the transition path to develop a digital technology-based business model if they do not produce their outputs in physical form, and are more related to information, such as media, banking, or insurance [13]. Firms that manufacture physical products experience challenging situations because 
the production processes and delivery value processes require direct contact. The latter group of firms has to stop production and distribution which results in revenue generation difficulties.

Meanwhile, manufacturing firms producing physical products that are categorized as essential needs-e.g., health products, food, beverage, energy products-can still run their operations, although there is some debate regarding the criteria for essential needs, which can vary between countries [29]. Therefore, companies that produce non-essential products or services must rely on creativity and agility because both these important factors differentiate them from competitors during a pandemic situation [13].

In response to this pandemic situation, many well-established firms have striven to upgrade their digital capabilities [3]. As a result, the group of firms that were initially left behind is able to narrow down the digital capabilities gap, compared to the new firms that were highly digitalized. Accordingly, the digital capabilities between the two groups have been blurred due to the stimulus caused by the pandemic. With the use of digital technologies, firms can improve their agility, so that they can adjust their business processes quickly, not in months but weeks, even days [1]. Therefore, it is important to understand that the transformation process of SMEs is due to external stimuli and occurs within limited time constraints. Firms must possess a certain level of agility to enable them to build the relevant capabilities for capitalizing on the opportunities arising from digitalization, and accordingly, they are able to withstand the pressure of environmental changes [13].

\subsection{Challenges of SMEs in the Time of the Pandemic}

In a disruptive business environment, long-established firms, that possess a strong position in the market, experience difficulties in achieving a balance between exploiting existing business models and exploring new business models $[6,30]$. The challenge of balancing these two capabilities arises because companies need to consider the core business with innovation, which often is not in accordance with organizational routines [11].

One of the obstacles to transforming a business model is the differences there can be between the perceptions of managers regarding environmental changes; it is difficult to form a convergent perception of managers toward environmental changes [17]. However, the emergence of the COVID-19 pandemic tends to make almost everyone believe that there is indeed a dramatic change in the business environment [2]. In fact, many believe that these changes will not only occur during the pandemic, but will also persist in the post-pandemic period $[2,15]$.

More than half of firms believe that the COVID-19 pandemic will have a large negative impact and, therefore, firms must act quickly [31]. The various challenges faced by SMEs include decreased customer purchasing power, restrictions on interaction and working hours, shortages of raw materials, cancellation of orders, cash flow difficulties, and supply chain disruption [10,32]. However, there are some companies that can take advantage of the pandemic. They are able to direct resources into creating business opportunities or what is called "disaster entrepreneurship" [33].

Established firms often face a dilemma when dealing with business model transformation. On the one hand, they must be able to take advantage of current opportunities by using existing business models, which is only short-term oriented. On the other hand, firms must create innovations that will maintain their survival [34]. It is the responsibility of top management to balance the short-term orientation, which tends to be synonymous with exploitation, and the long-term orientation that requires exploration. These issues are typically resolved with the use of an organizational design which can support business model transformation [18]. The process of finding a new organizational design can create differences of opinion among top management, which hinders firms in their pursuit of radical business model transformation [17].

The long-term impact of the COVID-19 pandemic is still difficult to foresee; scholars believe that post-pandemic opportunities will be even greater if firms can utilize digital technologies during the pandemic [10]. Such uncertainty is normal for managers of SMEs, who typically possess high entrepreneurial spirit, and for this reason, they are expected to have flexibility and adapt their 
business models in response to this environmental uncertainty [5]. To deal with this circumstance, many SMEs apply crisis management to build organizational resilience and recover their organizational functions to operate normally. Resilience includes the ability of an organization to maintain its normal organizational functions during periods of disruption [16]. It is expected that firms can achieve "a new kind of usual" regarding how to run a business [5]. The focus of this research is how the process of the SMEs can transform their business model to achieve a new kind of usual. Conducting analysis focusing on SMEs from the least developed country, where digital maturity varies highly between firms, and who manufacture various products which are not included in the essential category, will contribute to both knowledge on the subject and in the practical field.

\subsection{Open Innovation Dynamics and Business Model Innovation}

Firms could operate more than one business model and each business model is able to cross beyond the boundaries of the organizational structure to obtain the required resources, and hence, firms do not have to rely on the existing internal resources [30,35]. This circumstance encourages firms to adopt open innovation strategies, in which the firms involved in the business ecosystems and networks can support their business model innovation. The adoption of open innovation is complex; it requires a certain organizational culture [36,37], which largely consists of three main concepts: the entrepreneurship of novice entrepreneurs, the intrapreneurship of the employees, and organizational entrepreneurship [36]. SMEs are more well suited to these characteristics than large- sized firms, although the former have more alternatives to design resource configurations because they have more resources [15].

Well-established firms tend to maintain routines because they have a strong culture and, therefore, resist change. This group of firms will benefit from a stable business environment because they can use their capabilities to exploit predictable opportunities. Unfortunately, this strong culture could actually be an obstacle in their pursuit of change when they attempt to reconfigure the assets for pursuing business model innovation [36]. The reconfiguration of assets is often in conflict with those that are required to support existing business models, because some assets are typically utilized for different purposes [38]. An organizational culture that supports the aforementioned open innovation is more easily found in SMEs rather than large firms.

Open innovation is dynamic and can be viewed as a journey because it is not a single journey with a definite destination, but rather it is a continuous journey requiring constant adjustment [39]. Due to these characteristics, it shares some similarities with emergent strategy, as both concepts emphasize a non-linear, highly dynamic, evolving approach in responding to the rapidly changing business environment $[5,36]$. The proliferation of digital technologies plays a pivotal role in the practices of open innovation as these technologies support the communication that takes place between various parties operating in the same business ecosystem [40]. Meanwhile, during the time of crisis caused by the COVID-19 pandemic, the adoption of digital technologies has accelerated [15]. This could be a trigger for firms to adopt open innovation more easily as there are more parties now that are connected with the use of digital technologies, which are able to contribute to the firms' business models.

\section{Case Study Method}

\subsection{Case Study Design}

This research utilized a multiple case study design in order to observe the details and depth of phenomena under investigation in a natural setting. This method is considered to be appropriate for the development of an understanding of how phenomena develop in an organizational context [41]. The case study method that uses qualitative analysis is also considered to be the most relevant approach to theory development through the observation of constructs that develop in the real fields [42], especially for new topics [43]. To ensure both rigor and analytical generalization through the use of replication logic, this study used multiple case studies [44], with the polar sampling technique 
used to select the subjects [45]. The replication logics in the case study research are analogous to experimentations [46].

The polar sampling technique is different from statistical sampling, which is typically applied in management research that aims to test a theory $[39,40]$. The use of the polar sampling method is intended to develop analytical generalization, rather than statistical generalization, like ones in the survey that used quantitative methods [41]. Cross-case analysis among subjects that have a certain variation in characteristics ensures that generalization is achieved. This is a prerequisite for rigorous theory building that uses the case study method [45].

\subsection{The Case Study Companies}

This research was conducted in seven Indonesian SMEs, which manufacture different types of products and have different degrees of digital technology maturity level. The number of cases is within the range of the upper and lower level of optimum cases-i.e., twelve and two respectively. Using more than twelve cases makes it difficult for researchers to manage the rich qualitative data properly [46].

The seven case studies have been involved in our research project over the last three years in topics that are related to innovation, business models, and dynamic capabilities. Accordingly, we understand the research context well and the long-term relationship we have established with subjects has enabled us to communicate during the lockdown period. Both the profile of the case companies and the scope of the data collection are presented in Table 1.

\subsection{Data Collection}

Data collection, data presentation, and data analysis are iterative in nature and these processes are important elements in the case study method [41]. Although a clean slate is the most ideal condition for theory building, we used some of the previous empirical findings as priori constructs [45]. This approach is based on the "abduction" strategy where an iterative process occurs between the existing theory and the new theory that is being developed [47]. Apart from conducting semi-structured interviews with key informants from the case companies, we also had opportunities to make contacts with several customers, suppliers, and distributors when we carried out a field visit and observation. With this technique, we were better able to understand the research contexts.

To guide us during the interviews, so that the discussions went in the right direction, we prepared an interview protocol consisting of a question list that was based on priori constructs. Despite us preparing a list of questions for the interview guide, the interviews were undertaken flexibly so that new questions could emerge during the interviews, and we conducted field visits in case interesting issues emerged that were relevant to the subjects. Prior to the interviews, all the informants were informed that the interviews would be recorded and their identities were made anonymous. In addition, extensive field notes were made during the interviews to make it easier for researchers to analyze the data. The length of the interviews ranged from $30 \mathrm{~min}$ to just over $2 \mathrm{~h}$, depending on how the interviews were going. The first was conducted in early March, when COVID- 19 had just started in Indonesia, and the last was in mid-July 2020. Our interviews were deemed to be sufficient when we reached a point where the iterative process between data collection and data analysis did not generate a new code, but instead, reduplicated the existing dimensions [48]. 
Table 1. The case companies and scope of the data collection.

\begin{tabular}{|c|c|c|c|c|c|c|c|}
\hline Case Company & Fashion-Co. & Shellfish-CraftCo. & Contemporary-BatikCo. & Traditional-BatikCo. & RestaurantCo. & FurnitureCo. & HandicraftCo. \\
\hline Main products & Shoes and apparel & Seaweed handicraft & Contemporary Batik & Traditional batik & Food and beverage & Teak wood furniture & Wooden handicraft \\
\hline Employee size & 62 & 57 & 48 & 79 & 86 & 64 & 67 \\
\hline Annual sales & 900,000 USD & 150,000 USD & 170,000 USD & 250,000 USD & 675,000 USD & 1.2 million USD & 350,000 USD \\
\hline Target market & $\begin{array}{l}\text { Local, national, } \\
\text { and global }\end{array}$ & $\begin{array}{l}\text { Local, national, } \\
\text { and global }\end{array}$ & Local and national & Local and national & Local & $\begin{array}{l}\text { Local, national, } \\
\text { and global }\end{array}$ & $\begin{array}{l}\text { Local, national, } \\
\text { and global }\end{array}$ \\
\hline Founded & 1977 & 2016 & 2004 & 1999 & 2006 & 2000 & 1982 \\
\hline $\begin{array}{l}\text { Digital } \\
\text { technologies } \\
\text { adopted }\end{array}$ & $\begin{array}{l}\text { Firm's website, } \\
\text { social media, } \\
\text { online trading } \\
\text { platform, online } \\
\text { shop, email, } \\
\text { WhatsApp, } \\
\text { YouTube }\end{array}$ & $\begin{array}{l}\text { Firm's website, } \\
\text { social media, online } \\
\text { trading platform, } \\
\text { online shop, email, } \\
\text { WhatsApp, YouTube }\end{array}$ & $\begin{array}{l}\text { Social media, online } \\
\text { trading platform, email, } \\
\text { WhatsApp }\end{array}$ & $\begin{array}{l}\text { Social media, email, } \\
\text { WhatsApp }\end{array}$ & $\begin{array}{l}\text { Social media, } \\
\text { online trading } \\
\text { platform, email, } \\
\text { WhatsApp }\end{array}$ & WhatsApp & WhatsApp \\
\hline Informants & $\begin{array}{l}\text { Owner, supervisor, } \\
\text { marketing staff }\end{array}$ & $\begin{array}{l}\text { Owner, production } \\
\text { staff, marketing staff }\end{array}$ & $\begin{array}{l}\text { Owner, marketing staff, } \\
\text { accounting staff }\end{array}$ & $\begin{array}{l}\text { Owner, marketing } \\
\text { staff, marketing } \\
\text { supervisor, shop floor } \\
\text { staff }\end{array}$ & $\begin{array}{c}\text { Owner, chef, } \\
\text { stewardess, } \\
\text { customer, } \\
\text { customer service } \\
\text { staff }\end{array}$ & $\begin{array}{l}\text { Owner, production } \\
\text { staff, marketing staff }\end{array}$ & $\begin{array}{l}\text { Owner, shop } \\
\text { floor staff }\end{array}$ \\
\hline Informants & 8 & 9 & 4 & 6 & 10 & 8 & 4 \\
\hline Total interviews & 24 & 19 & 11 & 20 & 18 & 22 & 12 \\
\hline Field visits & 3 & 4 & 4 & 3 & 5 & 2 & 4 \\
\hline
\end{tabular}




\subsection{Data Analysis}

In this study, the data analysis adopted an inducto-deductive approach in which the researchers undertook constant iteration between data collection and analysis with the focus being on theory development [45]. The qualitative data obtained from the interviews were transcribed verbatim, and the data was then triangulated between the different informants to ensure its validity [41].

Data analysis was carried out with grounded theory, which consisted of three stages [49]. First, we conducted open coding, in which all the codes relevant to the research topics were documented. This process was repeated until it reached saturation point so that no new code emerged. Second, we carried out axial coding. At this stage, we identified the digital actions undertaken by the SMEs and we categorized them into different levels: non-use, orientation, preparation, testing, routines, and refinement and integration [50]. The list of the actions included not only activities related to the technology being implemented, but also supporting factors, such as technology investment, human resource allocation, the learning process etc. These factors also needed to be considered as various resources could easily be integrated with digital technology because it was categorized as general- purpose technology [1]. The final result of the second stage is that we succeeded in identifying the relationship between the emerging themes and the contexts, consequences, and interactions between the codes. The challenges and issues that were experienced by SMEs during the COVID-19 pandemic and the digital transformation strategies undertaken by the subjects were identified at this stage.

Third, we conducted selective coding and focused on the key themes by analyzing the interplays between the key themes. At this stage, we succeeded in grouping the challenges that were faced by SMEs during the COVID-19 pandemic into seven themes, and the digital transformation strategies implemented by SMEs into three major strategies: accelerated transition toward more digitalized firms, digitalizing sales for the firms' survival, and finding digital partners to reach the market.

\section{Empirical Findings and Analysis}

We conducted qualitative analysis to answer the first research question and the results are presented in Figure 1. The data structure presented in Figure 1 describes the findings from the interviews. These are presented as codes, themes, and dimensions, and from here, we identified strategies for carrying out digital transformation, which is the answer to the second research question. Based on the results of the qualitative data, we categorized the sample SMEs into three groups, based on the emerging problems they experienced, which is discussed below. The italicized texts, followed with the hashtag symbol-i.e., \#-and the number in brackets, indicate the key actions that are the main elements of this digital transformation; the list of actions is presented in Table 2. As shown in the table, the prominent actions by the case study firms are shown in the shaded area. These actions emerge from the coding, which we conducted using the grounded theory, as explained in Section 3.4.

\subsection{Group 1: "Ready to Jump" to a Digitalized Firm}

There was only one case study company that fell into this group: FashionCo. The SME in this category has a long history of adopting digital technology. In fact, it has adopted a hybrid business, which combines both online and offline, even though the offline business model is still more dominant. The COVID-19 pandemic has been a stimulus that has accelerated planned digital transformation. 


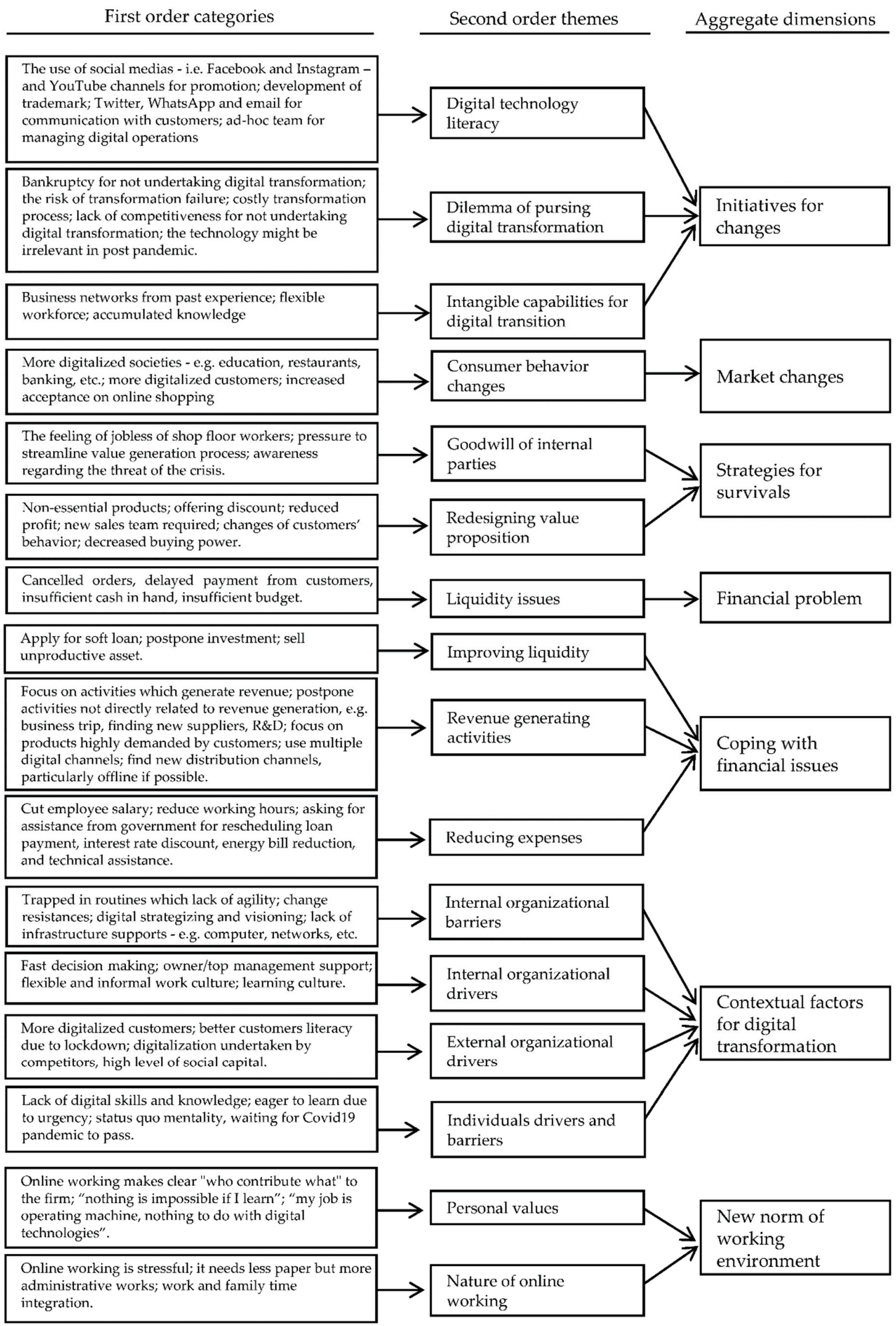

Figure 1. Data structure of the challenges experienced by small and medium enterprises (SMEs) during the pandemic. 
Table 2. List of key actions for pursuing digital business model transformation.

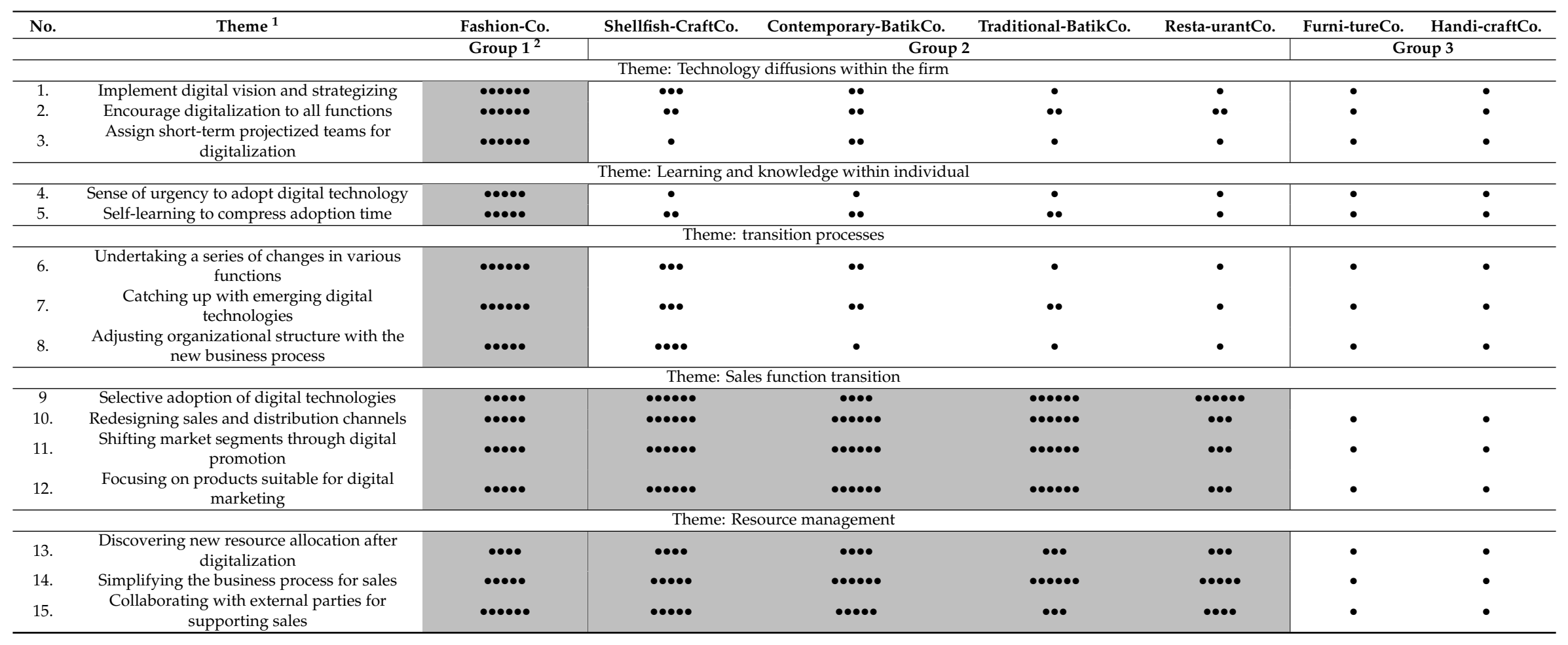


Table 2. List of key actions for pursuing digital business model transformation.

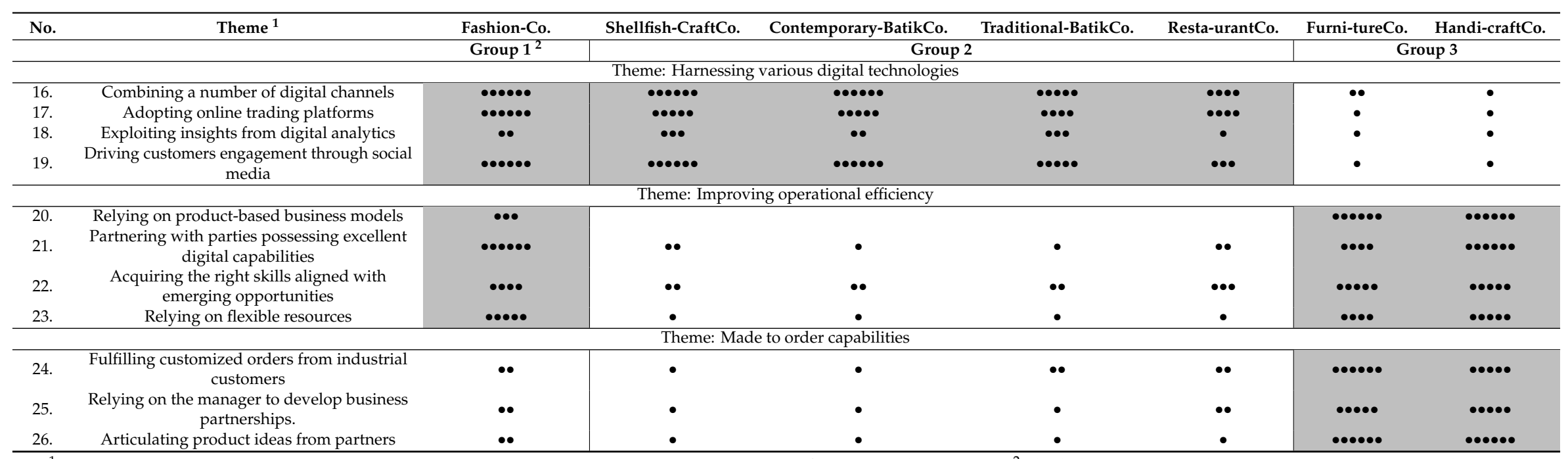

${ }^{1}$ Notes: • Non-use $\bullet \bullet$ : Orientation $\bullet \bullet \bullet$ Preparation $\bullet \bullet \bullet \bullet$ Testing; $\bullet \bullet \bullet \bullet \bullet, ~ R o u t i n e \cdot \bullet \bullet \bullet \bullet \bullet \bullet$ Refinement and integration. ${ }^{2}$ Shaded areas indicate the most prominent actions implemented by the case study firms in each group. Group 1: "Ready to jump" to a digitalized firm, case company FashionCo.; Group 2: Experiencing financial distress, case company: ShellfishCraftCo. ContemporaryBatikCo., TraditionalBatikCo., RestaurantCo.; Group 3: Lacking digital literacy but has rich social capital; case company: FurnitureCo., HandicraftCo. 
The case study firm combines entrepreneurial attitudes with digital strategizing, which requires a strong orientation toward digital culture. The owner of the firm has implemented digital visioning and strategizing (\#1). The company owners have a good conceptual understanding of the digital technology vision, as was indicated by their preparations for digitalization long before the emergence of the COVID-19 pandemic, as shown by the following statement:

"We are convinced that technology is the driver of change. As an established company, we do not feel much any changes that come from technology. But over time, society and market behavior changed. If we are not careful, after a while the market will be eroded and our customers will switch to competitors". (Marketing manager, FashionCo.)

Prior to the pandemic, the case company had implemented digitalization in its sales function, and when the pandemic emerged, it extended this adoption to other functions. The digitalization of business processes, for example, collaboration with the digital shopping platforms Lazada, Bukalapak, Blibli etc., has driven the market forward and encouraged other functions to adapt and adopt digital technologies. Moreover, the case company in this group has begun to encourage digitalization in various organizational functions (\#2), the majority of which relate to increasing automation and the standardization of business processes. Below is an expression of the informant describing this circumstance:

"We know that Facebook, Instagram, and Twitter are used in different ways, the purpose of their usage is different, and the algorithms used are different as well. There are some people who just link each other Facebook, Instagram, and Twitter without a clear idea what is the reason behind this linkage. They just do it. As a matter of fact, these social media are intended for different purposes. [They are used] not for selling as the first priority; but on the contrary, firstly [it is used for raising] awareness, after [it has been successfully raising] awareness, then [we can] offer a problem solution to customers". (Online marketing staff, FashionCo.)

The firm is able to understand the details of digital technologies because it is supported by a small ad-hoc team that has a specific task (\#3). This team is responsible for implementing digital technology in a structured manner with a project approach. The manager of the case company believes that waiting for the business environment to stabilize, and not making changes to business models is not a good decision; instead, he believes the firm's prospects could get worse if it does not immerse itself in the changes. Therefore, the manager attempts to instill a sense of urgency to master digital technology among individuals within the firm (\#4).

During the pandemic, there was no time for companies to train employees because they had to generate revenue generation within days. Companies benefited by the learning culture that has been created within the organization, which shortens the time it takes for technology to be adopted through self-learning. This culture has enabled the firm to compress the time taken for adoption to take place through self-learning (\#5). This learning culture has combined with a long history of digital knowledge within the firm, as explained below:

"Today's technology is different from those that were developed in the early 1990s. The logic of how the software works at that time still works for the current application. Even without being taught, I can, it is even faster and more effective if I study on my own because the current technology is more user-friendly". (Owner, FashionCo.)

This learning culture is seen as being a pivotal enabler of dynamic capabilities, particularly the ability to seize opportunities and perform transformation [1]. This digital transformation is undertaken through a series of changes carried out gradually (\#6), with each stage carried out within a short time period. This implementation is coordinated with an ad-hoc team, who is given a specific time period and assigned a specific task. In this way, this transformation process can be done in a more structured manner in which the company is clear about what it is attempting to achieve during each stage of the transformation. 
Digital technologies have enabled the firm to reach customers more easily, diversify its product lines, and shorten the product life cycles. Also, the firm realizes that new technology often makes business processes easier, faster, and cheaper. Therefore, the firm tries to catch up with emerging technologies (\#7) and harnesses them in creative ways. For example, one of the last actions of a case study company is to take advantage of the self-serve platform of TikTok to promote its products.

In line with the widespread technology adoption within the company, there has been an accelerated exchange of information and knowledge, leading to more efficient business processes. This adoption process has caused momentary disruption of the company's operations due to the changes required, but the newly-formed business process runs more efficiently after the adjustment. To support these business process changes, the firm undertakes an organizational structure adjustment with the new business process (\#8). This adjustment process is supported by flexible resources and individuals who are willing to carry out continuous learning.

\subsection{Group 2: Experiencing Financial Distress}

This group represents SMEs who experience financial distress-i.e., ShellfishCraftCo., ContemporaryBatikCo., TraditionalBatikCo., RestaurantCo.- and it seems this is the major issue experienced by the SMEs. The main priority of SMEs in this group is avoiding immediate collapse by conducting revenue generation. Two of the four SMEs in this group are retail firms, and are thus more vulnerable to economic uncertainty than supermarkets. All SMEs in this group agreed that they should take extraordinary steps to avoid collapse. For this reason, the firms push themselves to make decisions by investing in digital technologies. One of the informants described the emerging business conditions as follows:

"We are not sure whether digitalization will save us. But we are sure that if we don't digitize, we will definitely collapse. Even if digitalization fails, at least, digitalization will prolong our lives so that we have more time for preparation to overcome this situation with other steps". (Manager, ContemporaryBatikCo.)

SMEs in this group focus on digitizing the sales function because it organizes activities that generate revenue that can save the firms from collapse. The low digital maturity of the firms makes it too risky for them to implement digital technologies across all functions. Products that have been digitalized are also limited to a few categories that are suitable for online marketing. In short, the firm conducts selective digital technology adoption (\#9), as explained below:

"Don't just look at digitalization in a too simplistic way, as we need to look at the whole business model we have. We need to look at what needs to be digitalized and what doesn't need to be made digital.

For now, we are only digitizing functions that we really need it to keep us alive". (ShellfishCraftCo.)

To achieve the digitalization of the sales function, the SMEs redesigned its distribution and sales channels (\#10) from retail and boutique shops to online marketing. Due to this shift, tasks have been redesigned among the employees, with interconnected activities combined and assigned to the same staff. In a similar vein, resources were regrouped and allocated to do certain tasks to promote productivity and value. For example, some of the employees were previously assigned to serve customers at the boutique shop, they were assigned new tasks as online sales staff responsible for managing pre-sales, sales, and post-sales activities. Electricity and water bills decreased as the boutique's operating hours shortened. The firms decided to reduce production volume to avoid having excessive stocks of finished products. As a result, the trade-off between efficiency and resilience became apparent and the implementation of just-in-time was slightly neglected in order to ensure the firms' survival.

During the pandemic, there has been an increase in digital literacy among customers. In response to this change, the emphasis of the SMEs in this group was to modify the customer value proposition, because the focus of firms during the pandemic was on how to survive by maintaining stable sales 
volumes. This needs to be done by considering there has been a shift toward new customer segments (\#11) after the implementation of digital transformation, as explained in the following information:

"Technology not only changes how products are manufactured, but also the behavior of competitors, customers, and the business context. The existing customers may be our existing customers, but with new behavior, so that they are less relevant to the value delivery or value we offer currently". (Owner, TraditionalBatikCo.)

The SMEs case study in this group is still at an early stage of adopting digital technologies. In the meantime, there has been a shift in customers' behavior during the COVID-19 pandemic. In response to this circumstance, the case study companies focus on certain products suitable for digital marketing (\#12). Due to the early adoption of digital technology, the case study firms decided to select a technology that is easy to adopt and is the most supportive for generating revenue.

Digital technology adoption has encouraged the case study firms to discover new resource configurations (\#13) to improve their efficiency. The resources are focused on activities that are aimed at generating revenue and overriding activities not related to revenue, such as new supplier searching, new product development, and employee training. Digitalization helps firms to identify unseen opportunities about how to utilize existing resources and assets that belong to parties outside the firms.

To some extent, the adoption of digital technologies by serendipity helps firms to improve the value of output by combining the assets outside the firm with existing resources. Also, traditional activities which are in sequence are combined. For example, warehouse staff, who previously had duties to procure raw materials and manage the inventory only, have been given an additional task to service the delivery orders to customers who purchase online. All of these make the business process for sales simpler than the existing one. Activities that are not contributing to revenue generations are reduced and the business process for sales is simplified (\#14).

The case study firms want to grasp opportunities by adopting all the digital technologies that customers are most likely to use. Even though some case study firms have developed websites-i.e., ShellfishCraftCo.- the rest prefer to adopt online trading platforms (\#17) to support delivery value because the process of adopting it is much simpler. Some of the trading platforms selected by the SMEs case studies are, among others, Shopee, Lazada, Bukalapak, and Blibli. The adoptions of the trading platforms require firms to collaborate with external parties to support sales (\#15), including logistic service providers, electronic merchant services, electronic payment services etc.

The SMEs in this group are not ready yet for a digital transformation across all the functions within the organization. The total transformation cannot be achieved simply by developing a website. To overcome this issue, the case study firms combine several digital technologies simultaneously (\#16)—i.e., WhatsApp, e-mail, LINE, Facebook, Twitter, Instagram - to expand the customers' coverage. In some ways, the simultaneous adoption of several technologies is not always effective, but the case study firms are determined to do this to generate revenue as they are experiencing liquidity issues.

The case study firms are aware that a lot of data and information are available in the digital world; therefore, the managers strive to figure out how to retrieve the data and information to support the continuity of the business. There is no doubt that conducting detailed and thorough big data analysis will be expensive. Realizing the difficulty of conducting advanced big data analysis, the case study firms have focused on the adoption of digital technology that only requires a simple effort to exploit insights from digital analysis (\#18), such as utilizing social media to detect trend signals from market developments. For example, ShellfishCraftCo. created an ad-hoc team assigned to identify market trends that develop on social media through digital intelligence. This is called digital scouting, which consists of young staff with advanced technology capabilities [6]. The managers believe that firms should not focus on maximizing profits through the use of digital technologies, as profitability will follow if the firms succeed in providing value to customers during customer engagement. 
Our data analysis demonstrated that firms are able to adapt how they use social media properly and realize that social media is not only for introducing products or promoting products, but also to drive customers and communities' engagement through social media (\#19), as stated by the following informant:

"Social media is not only for product promotion, brand promotion, or product promotion. Using social media is not as simple as you think, like saying: tomorrow there is a $20 \%$ discount, then the day after tomorrow we will increase it to $50 \%$, and after that we have buy one get one free. That is not how it works. The first priority of using social media is how to build awareness, the second is to increase engagement, and then interact with the firms' followers". (Marketing staff, ShellfishCraftCo.)

\subsection{Group 3: Lacking Digital Literacy but Rich of Social Capital}

The two SMEs-i.e., FurnitureCo. and HandicraftCo.--included in this group have two main characteristics: the lowest level of digital literacy but a well-established social capital in their business ecosystem. SMEs in this group are looking for digital partners to overcome their very limited level digital literacy. The encouragement of digital strategizing in firms with very limited digital literacy is risky for the firm itself. This group of firms follows a different path in responding to the trend of digital transformation. A senior owner of an SME is quite confident about an alternative approach they are taking today, explaining:

"I understand that new firms are usually very aggressive, their managers think that it is compulsory to make their business online. They never think whether it is going to make profit or not, as long as they can go online, they feel safe from the threat of environmental changes. They think they can conquer the world with digital technology. But, please remember, I am from the baby boomer generation, I have gone through a long history of technological changes in different generations. I have proven to be more adaptive to changes [than them], enthusiasm is good for you to move forward, but if you have it too much, it will be dangerous". (Owner, HandicraftCo.)

SMEs in this group rely on a product-based business model (\#20). The firms focus on manufacturing products and selling them to customers. Managers realize that they have to follow the customer-centric trend but the problem is how to integrate this into the organizations' business processes. To cope with this issue, the firms collaborate with partners possessing excellent digital skills (\#21).

In addition, the SMEs in this group are supported by employees who have been working for a long time so that a creative attitude is embedded in the basic character, which is formed from the accumulation of knowledge over a long period. This kind of character cannot be formed through training or formal education. This basic character enables the staff to acquire skills that are aligned with emerging opportunities (\#22). This is how the manager describes this circumstance:

"I do not want to be greedy. I do not want to follow the mainstream to go online. I am sure those who are doing business online will come to me to purchase our products [and sell them online]. Our employees have a set of skills that other entrepreneurs do not have. When the market shifts, our products will also be able to shift, and we make that possible due to the skills of our people". (Owner, FurnitureCo.)

The creative attitude of the employees is, to some extent, strongly related to flexibility. With the use of flexible resources (\#23), the firms can target new customers by offering to use different product categories. Undeniably, the COVID-19 pandemic has driven new demands that never existed before. The following is an example where SMEs have shifted their target market to a new product category:

"A few days ago, we received orders for 10,000 face masks. Last week, we received an order for personal protective equipment from a hospital. We have never made both products before, but we can learn quickly to making such products. The expertise of our workforce can be transferred quickly across various products because they are very well experienced". (Owner, HandicraftCo.) 
Due to the nature of their production system, which is made to order, firms must be able to meet the production schedule with a tight production schedule. The majority of these orders come from industrial customers, who need products in large quantities, with a customized product design, and on a tight schedule (\#24). These orders do not come to the firms directly from customers, but with the assistance of partners. The partner's ability to find industrial customers who are willing to order products in large volumes is a pivotal factor that determines the success of the partnership. This partnership is unlikely to be successful if the orders come from individual customers because the number of orders will not achieve production economies of scale.

These partners, who have excellent digital capabilities, can act as the eyes and ears of the SMEs in this group. The partners will give early warnings to SMEs in case there are emerging signals of changes in the market. In this way, this group of SMEs still have access to emerging market trends. This communication also supports the managers, who are responsible for the firms' strategic and business directions. They are often trapped in routines, which can blind them to the need to adapt to changing environments. Communication with these partners can remind managers to become more sensitive, even though the firms do not adopt digital technologies, particularly during this pandemic period.

The managers of SMEs in this group are entrepreneurs, who are engaged in the business ecosystem that their firms operate in. Within this business ecosystem, the managers always seek opportunities to expand their networks with potential partners. These entrepreneurs occupy a unique position in the community, as they fulfill the needs of community members in different ways. It is undeniable that these managers, who are also the owners, have a dominant role in establishing business partnerships (\#25) with partners from the business ecosystem.

Company owners who have managed their firms for a long time are able to build partnerships with similar community members, as well as potential partners who are difficult to work with because of the knowledge gap barrier. These partners are typically start-up firms who possess expertise in digital technologies but lack product manufacturing knowledge. Through the partnership, managers of SMEs receive information regarding customer behavior from their partners, and the managers articulate it into product ideas and final products (\#26). During the midst of the pandemic, SMEs and start-ups were more willing to build a partnership as both parties realized that their business sustainability was in danger.

\section{Discussion}

In this study, it was found that the digital transformation of SMEs operating in creative industries does not necessarily involve radical business model transformation; the transformation can be implemented gradually and at different levels of changes [1]. All participants involved in this study agree that the impact of implementing digital transformation has made the firms more agile, which has resulted in more flexible resource allocation. However, this agile implementation is perceived as being costly and the firms' survival is at risk if it is not agile [51]. In addition, there is no "one size fits all solution" so firms must design their customized digital transformation path by considering "what strategy" to use and "where it should be adopted". The choice of strategy and the success of digital transformation depends on various factors, such as the firms' existing digital capabilities, learning culture, history of digital technology adoption, ability to develop with supporting parties, etc. Despite this, digital technology implementation varies a great deal, and this study identifies three paths for digital transformation strategies of the business model summarized in Table 3. The points presented in the table are the high-level findings from the cross-case analysis in Section 4, and are discussed against the existing literature in the following sub-sections. 
Table 3. Key features of three digital transformation types.

\begin{tabular}{|c|c|c|c|c|}
\hline Transformation Path & Key Features & Prerequisites & Consequences & Key Success Factor \\
\hline $\begin{array}{l}\text { Path 1: Accelerating transition } \\
\text { toward a more digitalized firm. } \\
\text { Adopted by firms in Group 1: } \\
\text { FashionCo. }\end{array}$ & $\begin{array}{l}\text { From a series of intermittent } \\
\text { processes undertaken over a } \\
\text { long period of time to } \\
\text { one-time digitalization, which } \\
\text { is executed in a short time. } \\
\text { Have adopted digital } \\
\text { technologies in various } \\
\text { functions before the pandemic } \\
\text { but to a limited degree. }\end{array}$ & $\begin{array}{l}\text { - Have put down the } \\
\text { foundation to carry out the } \\
\text { digital transformation } \\
\text { before the } \\
\text { COVID-19 pandemic. } \\
\text { Continuing and } \\
\text { accelerating the digital } \\
\text { transition that was } \\
\text { initiated before the } \\
\text { COVID-19 pandemic. }\end{array}$ & $\begin{array}{l}\text { Involves dramatic changes } \\
\text { and could result in a } \\
\text { sustainable } \\
\text { competitive position. } \\
\text { - Could be a risky transition. }\end{array}$ & $\begin{array}{l}\text { High level of digital } \\
\text { technology maturity. }\end{array}$ \\
\hline
\end{tabular}

Path 2: Digitalizing sales to ensure the firms' survival.

Adopted by firms in Group 2: ShellfishCraftCo.

ContemporaryBatikCo.,

TraditionalBatikCo.

RestaurantCo.
- Broadening the use of digital technologies from those merely intended for promotion to a comprehensive utilization of them for the sales function.

- $\quad$ Focusing on generating revenue for the firms' survival.
- Have been familiar with the basics of digital technologies, particularl social media for promotional purposes

- Have initiated the use of digital technologies for communication with customers.
- Moderate changes toward the firm.

- $\quad$ Temporary competitive advantages.
Creativity to understand the need of the markets-digital scouting, must have sharp eyes and ears.
- Some kind of "outsourcing" of the digital operations

Path 3: Finding digital partners to reach the market.

Adopted by firms in Group 3:

FurnitureCo., HandicraftCo. to partners.

- Focusing on the manufacturing, resource management, flexibility of resources to meet the market's requirements.
- $\quad$ Have engaged in business ecosystem and accumulated social capital.

- $\quad$ Possessing manufacturing flexibility, combined with knowledge accumulated from manufacturing various products for a wide variety of customers.
- Temporary solution to the firms' lack of

digital knowledge.

- At some point, the firm must acquire digital

knowledge and integrate digital technologies with the business models.
Ability to manage the relationship between the firms and partners. 


\subsection{Path 1: Accelerating Transition toward a More Digitalized Firm}

This path is only suitable for a firm that is "ready to jump" and become a digitalized firm. The only firm that falls into this group is FashionCo. The main characteristic of the firm in this category is that it has implemented its digital capabilities, such as online channels, websites, online shops, and it has collaborated with other parties to develop a digital business model [52]. It can be said that the SMEs in this category are the "first mover" group and strive to instill strategic sensitivity for the purpose of detecting weak signals of change before other companies can identify them. Digitalization was implemented rapidly, supported by a group of ad-hoc teams working with a project approach. In this approach, each project has a specific target and a certain time frame.

Digital technology is applied throughout the organizational functions but the depth of implementation varies between functions. Sales is the function with the most comprehensive digitalization because it had adopted digital technologies even before the pandemic began. When the pandemic started, the firm broadened its digitalization to various functions. It can be said that the pandemic acted as an external stimulus by threatening the firm's survival and creating awareness that made the firm respond quickly by accelerating digitalization.

Digital technology transformation undertaken rapidly offers a promising competitive advantage but it is high risk [3]. Nevertheless, in a digital technology environment, this competitive position will not last long as there is the potential of imitation by competitors [4]. This type of transformation requires firms to set up a digital technology foundation. This is combined with a digital visioning and strategizing, supported by a learning culture and the achievement of a certain level of digital technology literacy. In short, it is not an overnight transformation.

\subsection{Path 2: Digitalizing Sales for Firm Survival}

The second path is the most popular for SMEs, as indicated by the fact that more than half of the case companies fall into this group-i.e., ShellfishCraftCo., ContemporaryBatikCo., TraditionalBatikCo., RestaurantCo. The firms in this group digitalize their sales functions with the aim of generating revenue in more creative ways, although there is some doubt whether digital technology adoption will still be useful in the future after the pandemic ends.

The decision to carry out digital transformation in the sales function helps the firms to generate revenue by creating a customer experience [53], and they expect it to save them from the brink of bankruptcy. The literature demonstrated that staying close to customers increases the firm's chances of success [52] and the digital transformation of the sales function is a step that can achieve this aim. As a matter of fact, firms in this group have an interest in pursuing comprehensive digital transformation but, due to their low level of digital maturity, they decide to only digitalize the sales function.

The case study firms integrate product or service offerings through social media networks, which are equipped with consumer experience and supported by physical infrastructure for distribution, logistics and the supply chain [53]. All these strategies are intended to improve the firms' organizational agility. This cannot be achieved simply by developing an e-commerce website; instead, the firms need to create flexibility and efficiency by developing comprehensive back-office processes [15].

\subsection{Path 3: Finding Digital Partners to Reach Market}

The third path of the business model transformation demonstrated the transformation changes of how SMEs collaborate with their partners. Two case companies that lack digital literacy-i.e., FurnitureCo. and HandicraftCo.-fall into this group and have overcome their weakness by drowning themselves in digital technology ecosystems that have many enthusiastic partners to collaborate with. Digital technology transformation has changed the behavior of firms operating within the same business ecosystem [20] so that the business context of the firms has also had to change. These changes in business contexts can be supporting factors that enable the firms to continue their transition toward being more digitalized firms in the future. 
It has been proven that finding digital partners can solve those problems arising from a lack of digital literacy, but this is considered to be a short-term solution, as firms need to balance their shortterm decisions with long-term plans. At some point, the firms in this group must be able to adopt digital technologies without relying on their partners entirely. Constant redirection is needed so that the firms can respond properly to emerging trends in the short term, and at the same time, anticipate opportunities in the long term [6].

\subsection{Digitalization, Open Innovation, and Business Model Innovation of SMEs}

From the analysis in the previous sections, it is clear that the SME case studies have different levels of digital literacy, and therefore, the firms have different levels of readiness to pursue the business model transformation. The digital literacy level also affects the capability of firms to adopt open innovation. Open innovation can occur when firms combine their own internal resources with the technologies acquired from external partners to offer products to the market in new ways, which were never imagined by the firms who designed and manufactured the products [35].

The strategies of FurnitureCo. and HandicraftCo, which built partnerships with digital partner firms, could be categorized as open innovation practices because the parties who manage the digital technologies-i.e., the case companies' digital partners-are different from the parties who manufacture the products [35]. The partners manage and operate the digital technologies to match the specific needs of the case study firms and assist the SMEs in communicating with customers who need customized products. In short, the case companies take advantage of the digital technologies, which are managed and operated by external parties to create deliver customer value.

This study demonstrates that digital technology has enabled FurnitureCo. and HandicraftCo. to develop collective intelligence that facilitates the creation of creative business practices by entrepreneurs. Digital technologies have been documented as being enablers of open innovation, but that does not mean that firms with a lack of digital literacy cannot adopt open innovation. Similarly, digital technology literacy is not a compulsory requirement for firms who wish to pursue business model transformation. The case study firms with a minimum digital literacy can still do business model transformation by exploiting the social capital of the firms' owners, who have accumulated it from their long-time experience as entrepreneurs. A firm's social capital is more important than its digital technologies because the latter are only tools that function to convert the social capital into the firms' actions. These findings corroborate the existing literature by explaining that mediocre technologies, combined with a sophisticated business model, will provide more impactful results than advanced technology adopted by the poor business model [38].

\section{Conclusions and Future Research Directions}

This study demonstrates that SMEs follow three different major paths toward a digitalized firm: accelerating digitalization, digitalizing sales functions, and finding digital partners to reach the market. The decision to select one of the three digital transformation paths is determined by the existing digital maturity level, the learning culture, the history of digital technology adoption, etc. SMEs that manufacture customized products on a mass scale, and have a large physical size, can cope with low digital literacy issues by collaborating with digital firms as a shortcut. Meanwhile, direct interaction with customers is desperately needed for other product types, particularly fashion products with short life cycles. For this reason, sales function digitalization is compulsory. The digitalization of this function does not merely increase sales, it also develops customer experience.

In contrast, firms with a clear digital strategy and high digital maturity level can follow the first path. This path is not suitable for most SMEs as they are generally still at an early stage of adopting digital technology, whereas the digital transformation of a business model requires high digital maturity. Furthermore, firms in this group must have a long-term strategic digital vision and strategy. In short, the digital business model transformation in this path cannot be undertaken from scratch. 
This study found that the transformation path toward digitalized firms is idiosyncratic for each firm despite there being some generic strategies at a high level. The selected path is also dynamic in nature. As soon as the company identifies a pathway for digital transformation, there will be external changes that trigger the firms into readjusting their planned path. Whatever the path the firms attempt to follow, they need to dig deep into the organizational background and history as this is the basis of the managers' design organizational strategy, authority, and responsibility, including the values and norms that influence how business processes are carried out. These fundamentals factors determine how the transformation is undertaken, and how the changes that result from it can be absorbed into all elements of the organization.

In many cases, digital transformation results in customer alignment, and consequently improves efficiency. However, if competitors also undergo a similar transformation, so that they can interact with customers in new and better ways, then the organization could lose market share and sales. Thus, a digital transformation needs to be carried out continuously to ensure that the company's value delivery to customers is better than that of its competitors. To sum up, digital transformation is not a single point process, but rather, it is a moving target.

This study offers several insightful practical implications for managers. In line with the increase in the level of digitalization, the amount of data being managed gets bigger, which means firms require more resources to support their operations. Firms can cope with this issue by developing governance mechanisms for managing coordination and internal business processes. Nonetheless, it is not easy to assign a digital authority to a certain person in practice and separate that authority from other staff, as business processes are typically interconnected with one another. In addition, no one can predict when the pandemic will end. If it lasts for a long time, but the digital technology currently being used does not work any longer in the post-pandemic period, then managers will need to anticipate if there is resourced stickiness-i.e., a situation in which resources prefer to stay in existing business operations. To address this issue, firms can combine online and offline business, particularly how to develop synergies between the two-business models with the support of digital technologies. In addition, qualitative research aimed at developing a theory regarding the complex interplays between organizational design, strategy, and digital technologies will be interesting to investigate. These three concepts interact with one another and clarification regarding "what" affects "what" and the way in which they interplay with one another will offer an insightful contribution to knowledge development.

Author Contributions: Conceptualization, A.P. and A.M.; methodology, A.P. and A.M.; formal analysis, A.P. and V.N.A.O.P.; investigation, A.P. and V.N.A.O.P.; resources, V.N.A.O.P.; writing-original draft preparation, A.P.; writing-review and editing, A.P. and A.M.; data visualization, A.P.; project administration, V.N.A.O.P.; funding acquisition, A.P. All authors have read and agreed to the published version of the manuscript.

Funding: The authors are very grateful to the Directorate of Research and Community Services, Universitas Islam Indonesia that provided financial support to conduct this research through the JIH Research Grant contract number 01/Dir/DPPM/70/Pen.Unggulan.JIH Research Grant/2020.

Acknowledgments: The authors would like to thank Indra Putra Nugraha for discussions during his research stays at our university which led us to a more comprehensive analysis.

Conflicts of Interest: The authors declare no conflict of interest.

\section{References}

1. Björkdahl, J. Strategies for digitalization in manufacturing firms. Calif. Manag. Rev. 2020, 1-20. [CrossRef]

2. Sein, M.K. The serendipitous impact of Covid-19 pandemic: A rare opportunity for research and practice. Int. J. Inf. Manag. 2020, in press. [CrossRef] [PubMed]

3. Li, F. Leading digital transformation: Three emerging approaches for managing the transition. Int. J. Oper. Prod. Manag. 2020, ahead-of-print. [CrossRef]

4. Li, F. The digital transformation of business models in the creative industries: A holistic framework and emerging trends. Technovation 2018, 102012. [CrossRef] 
5. Doern, R.; Williams, N.; Vorley, T. Special issue on entrepreneurship and crises: Business as usual? An introduction and review of the literature. Entrep. Reg. Dev. 2019, 31, 400-412. [CrossRef]

6. Warner, K.S.; Wäger, M. Building dynamic capabilities for digital transformation: An ongoing process of strategic renewal. Long Range Plan. 2019, 52, 326-349. [CrossRef]

7. Dubey, R.; Gunasekaran, A.; Childe, S.J.; Blome, C.; Papadopoulos, T. Big data and predictive analytics and manufacturing performance: Integrating institutional theory, resource-based view and big data culture. Br. J. Manag. 2019, 30, 341-361. [CrossRef]

8. Gupta, G.; Bose, I. Digital transformation in entrepreneurial firms through information exchange with operating environment. Inf. Manag. 2019, 103243. [CrossRef]

9. Richter, A. Locked-down digital work. Int. J. Inf. Manag. 2020, 102157. [CrossRef]

10. Kuckertz, A.; Brändle, L.; Gaudig, A.; Hinderer, S.; Reyes, C.A.M.; Prochotta, A.; Steinbrink, K.; Berger, E.S. Startups in times of crisis-A rapid response to the COVID-19 pandemic. J. Bus. Ventur. Insights 2020, 13, e00169. [CrossRef]

11. Sund, K.J.; Bogers, M.; Villarroel, J.A.; Foss, N. Managing tensions between new and existing business models. MIT Sloan Manag. Rev. 2016, 57, 8-10.

12. Remane, G.; Hanelt, A.; Nickerson, R.C.; Kolbe, L.M. Discovering digital business models in traditional industries. J. Bus. Strat. 2017, 38, 41-51. [CrossRef]

13. Seetharaman, P. Business models shifts: Impact of Covid-19. Int. J. Inf. Manag. 2020, 54, 102173. [CrossRef] [PubMed]

14. Snihur, Y.; Wiklund, J. Searching for innovation: Product, process, and business model innovations and search behavior in established firms. Long Range Plan. 2019, 52, 305-325. [CrossRef]

15. Fletcher, G.; Griffiths, M. Digital transformation during a lockdown. Int. J. Inf. Manag. 2020, in press. [CrossRef] [PubMed]

16. Williams, T.A.; Gruber, D.A.; Sutcliffe, K.M.; Shepherd, D.A.; Zhao, E.Y. Organizational response to adversity: Fusing crisis management and resilience research streams. Acad. Manag. Ann. 2017, 11, 733-769. [CrossRef]

17. Egfjord, K.F.H.; Sund, K.J. Do you see what I see? How differing perceptions of the environment can hinder radical business model innovation. Technol. Forecast. Soc. Chang. 2020, 150, 119787. [CrossRef]

18. Leih, S.; Linden, G.; Teece, D.J. Business model innovation and organizational design: A dynamic capabilities perspective. In Business Model Innovation: The Organizational Dimension, 1st ed.; Foss, N.J., Saebi, T., Eds.; Oxford University Press: Oxford, UK, 2015; pp. 1-19.

19. Leonard-Barton, D. Core capabilities and core rigidities: A paradox in managing new product development. Strat. Manag. J. 1992, 13, 111-125. [CrossRef]

20. Teece, D.J. Explicating dynamic capabilities: The nature and microfoundations of (sustainable) enterprise performance. Strat. Manag. J. 2007, 28, 1319-1350. [CrossRef]

21. Winterhalter, S.; Zeschky, M.B.; Gassmann, O. Managing dual business models in emerging markets: An ambidexterity perspective. RED Manag. 2015, 46, 464-479. [CrossRef]

22. Sohl, T.; Vroom, G.; Fitza, M.A. How much does business model matter for firm performance? A variance decomposition analysis. Acad. Manag. Discov. 2020, 6, 61-80. [CrossRef]

23. Svahn, F.; Mathiassen, L.; Lindgren, R. Embracing digital innovation in incumbent firms: How Volvo cars managed competing concerns. MIS Q. 2017, 41, 239-253. [CrossRef]

24. Hasenpusch, T.C.; Baumann, S. Strategic media venturing: Corporate venture capital approaches of TIME incumbents. Int. J. Media Manag. 2017, 19, 77-100. [CrossRef]

25. Sebastian, I.M.; Ross, J.W.; Beath, C.; Mocker, M.; Moloney, K.G.; Fonstad, N.O. How big old companies navigate digital transformation. MIS Q. Exec. 2017, 16, 197-213.

26. Osterwalder, A.; Pigneur, Y. Business Model Generation: A Handbook for Visionaries, Game Changers, and Challengers; John Wiley \& Sons: Hoboken, NJ, USA, 2010.

27. Björkdahl, J. Technology cross-fertilization and the business model: The case of integrating ICTs in mechanical engineering products. Res. Policy 2009, 38, 1468-1477. [CrossRef]

28. Teece, D.J. Business models, business strategy and innovation. Long Range Plan. 2010, 43, 172-194. [CrossRef]

29. Wilson, C. Coronavirus: Shoppers Face 'Essential Items' Confusion. BBC News. Available online: https: //www.bbc.com/news/uk-52097797 (accessed on 20 August 2020).

30. Teece, D.J. Business models and dynamic capabilities. Long Range Plan. 2018, 51, 40-49. [CrossRef] 
31. Thorgren, S.; Williams, T.A. Staying alive during an unfolding crisis: How SMEs ward off impending disaster. J. Bus. Ventur. Insights 2020, 14, e00187. [CrossRef]

32. Turner, J.; Akinremi, T. The business effects of pandemics-A rapid literature review. In ERC Insight Paper; University of Warwick: Coventry, UK, 2020.

33. Linnenluecke, M.K.; McKnight, B. Community resilience to natural disasters: The role of disaster entrepreneurship. J. Enterprising Communities People Places Glob. Econ. 2017, 11, 166-185. [CrossRef]

34. Day, G.S.; Schoemaker, P.J.H. Adapting to fast-changing markets and technologies. Calif. Manag. Rev. 2016, 58, 59-78. [CrossRef]

35. Yun, J.J. Business Model Design Compass: Open Innovation Funnel to Schumpeterian New Combination Business Model Developing Circle; Springer: Singapore, 2017.

36. Yun, J.J.; Zhao, X.; Jung, K.; Yigitcanlar, T. The culture for open innovation dynamics. Sustainability 2020, 12, 5076. [CrossRef]

37. Yun, J.J.; Won, D.; Park, K. Entrepreneurial cyclical dynamics of open innovation. J. Evol. Econ. 2018, 28, 1151-1174. [CrossRef]

38. Chesbrough, H. Business model innovation: Opportunities and barriers. Long Range Plan. 2010, 43, 354-363. [CrossRef]

39. Chiaroni, D.; Chiesa, V.; Frattini, F. The open innovation journey: How firms dynamically implement the emerging innovation management paradigm. Technovation 2011, 31, 34-43. [CrossRef]

40. Yun, J.J.; Liu, Z. Micro-and macro-dynamics of open innovation with a quadruple-helix model. Sustainability 2019, 11, 3301. [CrossRef]

41. Yin, R.K. Case Study Research: Design and Methods, 4th ed.; Sage Publications, Inc.: London, UK, 2014.

42. Eisenhardt, K.M. Better stories and better constructs: The case for rigor and comparative logic. Acad. Manag. Rev. 1991, 16, 620-627. [CrossRef]

43. Edmondson, A.C.; McManus, S.E. Methodological fit in management field research. Acad. Manag. Rev. 2007, 32, 1155-1179. [CrossRef]

44. Eisenhardt, K.M.; Ott, T.E. Rigor in theory building from multiple cases. In The Routledge Companion to Qualitative Research in Organization Studies, 1st ed.; Mir, R., Jain, S., Eds.; Routledge: New York, NY, USA, 2017; pp. 79-91.

45. Eisenhardt, K.M. Building theories from case study research. Acad. Manag. Rev. 1989, 14, 532-550. [CrossRef]

46. Volmar, E.; Eisenhardt, K.M. Case study research: A state-of-the-art perspective. In Oxford Research Encyclopedia of Business and Management; Aldag, R.J., Ed.; Oxford University Press: Oxford, UK, 2020; pp. 1-20. [CrossRef]

47. Eisenhardt, K.M.; Graebner, M.E. Theory building from cases: Opportunities and challenges. Acad. Manag. J. 2007, 50, 25-32. [CrossRef]

48. Glaser, B.G.; Strauss, A.L. Discovery of Grounded Theory: Strategies for Qualitative Research; Routledge Publisher: New York, NY, USA, 1967.

49. Bamford, D. The use of grounded theory in change management research. J. Chang. Manag. 2008, 8, 111-121. [CrossRef]

50. Hall, G.E.; Loucks, S.F.; Rutherford, W.L.; Newlove, B.W. Levels of use of the innovation: A framework for analyzing innovation adoption. J. Teach. Educ. 1975, 26, 52-56. [CrossRef]

51. Teece, D.; Peteraf, M.; Leih, S. Dynamic capabilities and organizational agility: Risk, uncertainty, and strategy in the innovation economy. Calif. Manag. Rev. 2016, 58, 13-35. [CrossRef]

52. Guenzi, P.; Habel, J. Mastering the digital transformation of sales. Calif. Manag. Rev. 2020, 0008125620931857. [CrossRef]

53. Berman, S.J. Digital transformation: Opportunities to create new business models. Strat. Leadersh. 2012, 40, 16-24. [CrossRef]

(C) 2020 by the authors. Licensee MDPI, Basel, Switzerland. This article is an open access article distributed under the terms and conditions of the Creative Commons Attribution (CC BY) license (http://creativecommons.org/licenses/by/4.0/). 